\title{
Risk factors in breast cancer: can we change something
}

\begin{abstract}
Breast cancer is the commonest cancer of urban Indian women and the second commonest in the rural women. Age incidence rates in India suggest that the disease peaks at a younger age (eg, 40-50 years) than in Western countries. Owing to the lack of awareness of this disease and in absence of a breast cancer screening program, the majority of breast cancers are diagnosed at a relatively advanced stage. That lifestyle changes can change the risk of developing breast cancer is supported by several lines of evidence. The rates of breast cancer vary widely by the geographic areas around the world and only a small part of these differences is due to genetics. Over a period of time within-country changes in breast cancer incidence has been seen to be paralleled by lifestyle and behavior changes. The risk of breast cancer may be lowered to the extent that one can make lifestyle changes consistent with modifiable risk factors. In addition, healthy lifestyle choices such as limiting alcohol intake, maintaining a healthy body weight, high dietary soy intake and engaging in regular physical activity may help lower one's risk.
\end{abstract}

Keywords: breast cancer, risk, life style, countries, rising, cancer, awareness, deaths, ethnic, cultura
Volume 7 Issue I - 2019

\section{Zahoor Ahmed}

Department of Surgical Oncology, University of SMHS HOSPITAL, India

\author{
Correspondence: Zahoor Ahmed, Department of Surgical \\ Oncology, University of SMHS Hospital, SMHS hospital Srinagar \\ $\mathrm{J}$ and K, India, Tel 880394223I.
}

Email Drahmedzahoor@gmail.com

Received: February 08, 2018 | Published: February 20, 2019

\section{Introduction}

Breast cancer is the commonest cancer in women worldwide with a widely variable incidence between countries and regions. The developed countries with a small proportion of the world population account for almost $50 \%$ of breast cancers diagnosed worldwide. ${ }^{1}$ The incidence of breast cancer is low in India, but rising. Breast cancer is the commonest cancer of urban Indian women and the second commonest in the rural women. ${ }^{2}$ Owing to the lack of awareness of this disease and in absence of a breast cancer screening program, the majority of breast cancers are diagnosed at a relatively advanced stage. India is a sub-continent with wide ethnic, cultural, religious, and economic diversity and variation in the health care infrastructure. The health care facility pattern is heterogeneous, with numerous regions where the benefits of the awareness, early diagnosis, and multidisciplinary treatment programs have not reached. As per the ICMR-PBCR data, breast cancer is the commonest cancer among women in urban registries of Delhi, Mumbai, Ahmedabad, Calcutta, and Trivandrum where it constitutes $>30 \%$ of all cancers in females. ${ }^{2}$ In India, breast cancer is the second most common cancer (after cervical cancer) with an estimated 115,251 new diagnoses and the second most common cause of cancer-related deaths with 53,592 breast cancer deaths in $2008 .^{3}$ The age-standardized incidence rate for breast cancer in India is 22.9 per 100,000 , one-third that of Western countries, and the mortality rates are disproportionately higher. ${ }^{3}$ Breast cancer accounts for $22.2 \%$ of all new cancer diagnoses and $17.2 \%$ of all cancer deaths among women in India. Breast cancer in urban areas of India is three times higher than in rural parts of the country. ${ }^{4}$

Studies have shown a rising trend in the incidence of breast cancer in India with steadily increasing rates since the mid-1980's with the largest increases observed in Mumbai. ${ }^{5,6}$ The increasing burden of disease may be associated with lifestyle factors such as later age at marriage, age at first birth, reduced breastfeeding and westernization of diet and physical activity patterns. ${ }^{7,8}$ Marriage at an early age, early and multiple childbirths, and breastfeeding of all children for a long period of time is the norm in most Indian societies. However, the urban educated class is moving away from this trend, with lateage childbirth and little or no breastfeeding due to changing social values and the demands of jobs on working women. Breast cancer rates tend to be higher in women of higher education and in specific communities that have adopted a more westernized lifestyle, such as the Christians and the Parsis. These changes may be partly responsible for the increasing trend of breast cancer incidence.

It has been established that one of the strongest predictors of women risk of breast cancer are: increasing age, geographic region, family history of this disease and genetic factors such as mutations in BRCA1 and BRCA2 genes and in other high-penetrance genes (e.g., p53). ${ }^{9,10}$ The next well established factors that increase breast cancer risk included exposure on ionizing radiation in childhood, lifetime exposure to endogenous sex hormones determined by reproductive factors. Over the past two decades numerous investigations have focused on the possible role of lifestyle factors. Strong evidence exists that oral contraceptives (OCP) recent use, hormonal replacement therapy (HRT), smoking, physical inactivity, increased alcohol consumption (about 1 drink/day, $\approx 10 \mathrm{~g}$ alcohol), obesity (in postmenopausal women), diet rich in high saturated fatty acids and red meat are associated with increased breast cancer risk. Studies have also found a positive association between experience of psychological stress and breast cancer risk. ${ }^{11}$ Recognized breast cancer risks contribute to a better understanding of etiology of the disease but they only explain a small proportion of cancer patients. It is known that physical activity, diet, energy intake and body weight exert effect on breast cancer risk independently as well as these determinants of lifestyle undergo complex interaction. ${ }^{12}$ Similarly, reproductive factors are also interrelated. Furthermore, mechanisms responsible for developing breast cancer may be different among subgroups of women, e.g. in pre- and post-menopausal women. Some of behavioral risk factors may be easily modified; thereby their modification may play an important role in the prevention of breast cancer. ${ }^{13}$

The most important modifiable and non-modifiable risk factors are as follows 


\section{Non-modifiable risk factors}

Age, height, Personal history of benign breast or other breast disease, family history, BRCA1/BRCA2 mutations, menstrual history, Breast density on mammogram, exposure to radiation

\section{Modifiable risk factors}

Age at first child, hormone replacement therapy, breast feeding

\section{Lifestyle and dietary factors}

Socioeconomic status: Women of higher socioeconomic status are at greater risk for breast cancer, with as much as a twofold increase in incidence from lowest to the highest strata. This is thought to reflect differing reproductive patterns with respect to parity, age at first birth, age at menarche, smoking, and utilization of screening mammography. ${ }^{14}$

Weight: Weight and body mass index (BMI) have opposite influences on postmenopausal as compared to premenopausal breast cancer. Higher weight/BMI and postmenopausal weight gain have been associated with a higher risk of breast cancer in multiple studies. ${ }^{15-17}$ Expressed in terms of BMI, women with a BMI $>33 \mathrm{~kg} /$ $\mathrm{m}^{2}$ had a 27 percent increased breast cancer risk compared to those with a BMI $<21 \mathrm{~kg} / \mathrm{m}^{2}$. Prospective cohort studies have found an inverse association between obesity and premenopausal breast cancer. Premenopausal women with a BMI $\geq 31 \mathrm{~kg} / \mathrm{m}^{2}$ were 46 percent less likely to develop breast cancer than those with a BMI $<21 \mathrm{~kg} / \mathrm{m}^{2} .{ }^{15}$ The biologic mechanisms underlying this association are unclear.

Height: In the majority of studies, increased height has been associated with a higher risk of both premenopausal and postmenopausal breast cancer. ${ }^{15,16}$ Women who were at least $175 \mathrm{~cm}$ (69 inches) tall were 20 percent more likely to develop breast cancer than those less than $160 \mathrm{~cm}$ (63 inches) tall. ${ }^{15}$

Physical activity: Regular physical exercise appears to provide modest protection against breast cancer. ${ }^{18,19}$ Some studies have shown a decreased risk of premenopausal breast cancer in women who exercise more, particularly during adolescence but others have shown no difference. ${ }^{18,20}$ In premenopausal women, even moderate physical activity can be associated with an ovulatory cycles, which are associated with decreased risk. Among postmenopausal women, the data more consistently show a protective effect of regular strenuous activity on breast cancer incidence. The benefit of physical activity was most pronounced in women who performed strenuous exercise at age 35 compared to a younger (age 18) or older (age 55) age and in women who currently engaged in the equivalent of 10 hours or more per week of brisk walking. ${ }^{21}$

Smoking: Accumulating evidence supports an association between active and passive tobacco smoking and increased breast cancer risk, particularly in premenopausal women. ${ }^{22}$ Increased risks are most consistent in studies for early initiation, longer duration and/ or higher pack-years of smoking. ${ }^{23}$

\section{Dietary factors}

a. Alcohol: Intake of alcohol is associated with an increased risk of hormone receptor-positive breast cancer, and the effect appears to be additive with hormone therapy. There is evidence of a doseresponse relationship for example as little as one to two drinks per day can increase risk. One combined analysis of data from
53 studies around the world estimated that the relative risk for breast cancer increased 7\% for each additional $10 \mathrm{~g}$ of alcohol consumed daily. ${ }^{24}$

b. Fat intake: Animal and ecologic studies have shown a positive correlation between fat consumption and increased breast cancer risk. However, the results of case-control and prospective cohort studies have been mixed. In a prospective Diet and Health Study, women with fat intake of $90 \mathrm{~g}$ /day (40 percent of total calories from fat) had rates of invasive breast cancer that were 11 to 22 percent higher than those of women with median fat intake of $24.2 \mathrm{~g}$ /day (20 percent of calories from fat) ${ }^{25}$ While intake of dietary fat per se has not been established as associated with risk for breast cancer, increased dietary fat typically increases caloric intake. This results in obesity which is risk factor for breast cancer.

c. Red meat: An association between intake of red meat ( $>5$ servings per week) and ER/PR-positive premenopausal breast cancer has been observed. ${ }^{26,27}$

d. Calcium/vitamin D: Several studies suggest that intake of lowfat dairy products may protect against breast cancer, mainly in premenopausal women. ${ }^{28,29}$ However studies in postmenopausal women did not find a strong association between dairy intake and breast cancer risk. ${ }^{30}$ Calcium (1000 mg daily) plus vitamin D (400 international units daily) did not report any significant influence of supplementation on breast cancer risk in postmenopausal women. ${ }^{31}$

e. Phytoestrogens: Phytoestrogens are naturally occurring plant substances with a chemical structure similar to 17-beta estradiol. They consist mainly of isoflavones (found in high concentrations in soy beans and other legumes) and lignins (found in a variety of fruits, vegetables, and cereal products). The high soy intake and low rates of breast cancer in Asian populations led to the hypothesis that soy consumption might decrease breast cancer risk by displacing estradiol and functioning as a relative antiestrogen. Meta-analysis showed that higher intake of isoflavones ( $\geq 20 \mathrm{mg}$ per day as compared to lower intake of about $5 \mathrm{mg}$ per day) was associated with a 29 percent reduction in breast cancer risk. $^{32}$

f. Antioxidants: There is no strong evidence for an effect of intake of vitamin $\mathrm{E}$, or $\mathrm{C}$ or beta-carotene on breast cancer risk. Some studies on selenium suggest that the lowest levels may be associated with an increased risk, but higher levels are not protective. $^{33}$

g. Caffeine: There is no association between caffeine intake and breast cancer risk. ${ }^{34}$

\section{Reproductive/hormonal risk factors}

Prolonged exposure and higher concentrations of endogenous estrogen increases the risk of breast cancer.

Age at menarche and menopause: Younger age at menarche is associated with a higher risk of breast cancer. ${ }^{35,36}$ In one study, for every two-year delay in the onset of menarche, there was a 10 percent reduction in cancer risk. ${ }^{36}$ Later menopause increases breast cancer risk. The relative risk increases by 1.03 percent for each year older at menopause, which is comparable to the increase with HT use. ${ }^{35,37}$ Bilateral oophorectomy before the age of 40 reduces lifetime risk by 50 percent. $^{38}$ 
Menstrual patterns/infertility: Several epidemiologic studies suggest a link between infertility due to an ovulatory disorders and a decreased risk of breast cancer, but the results are inconsistent. ${ }^{39,40}$

Parity: Nulliparous women are at increased risk for breast cancer compared with parous women; the relative risk ranges from 1.2 to 1.7..$^{35,41}$ The protective effect of pregnancy is seen after 10 years following delivery. ${ }^{42}$ Majority of studies suggest a decreased risk with increasing number of pregnancies.

Age at first birth: The younger a woman is at her first full-term pregnancy, the lower her breast cancer risk. The cumulative incidence of breast cancer up to age 70 for parous versus nulliparous women was 20 percent lower if the first birth was at age 20,10 percent lower for first birth at age 25, and 5 percent higher if the first birth was at age $35 .{ }^{41}$ The risk for a woman with a first full term birth at age 30 is similar to that of a nulliparous woman. The effect of early first live birth is that full cellular differentiation, which occurs in the gland during and after pregnancy, protects the breast from breast cancer development. ${ }^{35}$

Abortion: Since abortion disrupts the maturation process of the breast, it has been hypothesized to increase breast cancer risk. Both a large pooled analysis and population-based cohort studies do not support an association between abortion (induced or spontaneous) and breast cancer risk. ${ }^{43,44}$

Breastfeeding: A protective effect of breastfeeding has been shown in multiple case-control and cohort studies, the magnitude of which may be dependent on the duration of breastfeeding and on parity. Data from 47 epidemiologic studies including 50,302 women with invasive breast cancer and 96,973 controls estimated that the relative risk of breast cancer was reduced by $4.3 \%$ for every 12 months of breastfeeding, in addition to a decrease of 7 percent for each birth. ${ }^{45}$ Breastfeeding delays the reestablishment of ovulatory cycles and increases prolactin secretion with a concomitant decrease in estrogen production.

Endogenous hormone levels: Obese postmenopausal women have higher estrogen levels than non-obese postmenopausal women, due to the conversion of adrenal androgens to estrogens in fatty tissue. Obese postmenopausal women have a higher risk of breast cancer and reducing estrogen levels (by suppressing ovarian function in premenopausal women or use of drugs such as aromatase inhibitors in postmenopausal women) lowers breast cancer risk. In a study of 7705 postmenopausal women, those with highest tertile of serum estradiol levels $(>12 \mathrm{pmol} / \mathrm{L})$ had a two-fold higher risk of invasive breast cancer than women with lower levels. ${ }^{46}$ The data in premenopausal women are less clear, in part due to the inter-individual and intraindividual variability of hormone concentrations during menstrual cycles. A significant association between serum estrogen levels during the follicular phase of the menstrual cycle and breast cancer risk was shown in a case control study. ${ }^{47}$

Bone density: Because bone contains estrogen receptors and is highly sensitive to circulating estrogen levels, bone mineral density (BMD) may be a surrogate marker for long-term exposure to endogenous estrogen. In multiple studies, women with higher bone density had a higher breast cancer risk. ${ }^{48}$

Breast density: The extent of dense tissue within the breast is variable within the population. Although largely an inherited trait, there appears to be a potentially modifiable component. ${ }^{49}$ Hormone therapy increases breast density while tamoxifen decreases it.
Exogenous hormone factors: Much of the available evidence supports a causal relationship between exogenous hormone therapy and breast cancer. Long-term use has been associated with the highest risk. On the other hand, short-term use of combined estrogenprogestin therapy appears not to increase the risk of breast cancer significantly. Multiple observational studies have shown an increased risk of breast cancer with postmenopausal hormone therapy, which includes unopposed estrogen therapy and combined estrogenprogestin therapy. ${ }^{50,51}$ Furthermore, a reanalysis of original data from 51 epidemiologic studies comprising 52,705 women with and 108,411 women without breast cancer found that for each year a woman uses postmenopausal hormones, her risk of breast cancer increases by 2.3 percent. ${ }^{50}$ The relative risk of developing cancer was 1.35 for women who were current hormone users and had taken hormones for five years or longer compared with never users. Greater breast cancer risk was observed with initiation of estrogen-progestin therapy close to menopause, earlier the therapy started higher the risk. ${ }^{52}$ Epidemiologic studies have generally not demonstrated an association between OC use and the risk of breast cancer later in life. Nocturnal light exposure/ Night shift work. At least three studies and a meta-analysis support an association between exposure to light at night and the risk of breast cancer. ${ }^{53,54}$ A meta-analysis exploring the relationship between night work and breast cancer risk included 13 reported studies of airline cabin attendants and nighttime shift workers. The relative risk for all studies combined was $1.48 .{ }^{55}$ Exposure to light at night suppresses the normal nocturnal production of melatonin by the pineal gland but the primary mechanisms for the association between melatonin and breast cancer risk are unknown. Shift work is now recognized by IARC/WHO as a probable carcinogen. ${ }^{56}$ For women who are already at higher than average risk, their risk of developing breast cancer can be reduced by at least 50 percent or more by taking tamoxifen or raloxifene for five years. Tamoxifen and raloxifene are both approved by the United States Food and Drug Administration (FDA) for the prevention of breast cancer.

\section{Conclusion}

Men are more than one hundred times less likely to get breast cancer than women. There are several approaches that women can take to decrease their risk of breast cancer. These include lifestyle changes (eg, minimize use of postmenopausal hormones, childbearing at a younger age, breastfeeding for at least six months, avoidance of adult weight gain, limiting alcohol consumption, avoidance of smoking, regular physical activity), chemoprevention with tamoxifen or raloxifene, and early detection through adherence to recommendations for screening mammography.

\section{Acknowledgments}

None.

\section{Conflicts of interest}

Author declares that there are no conflicts of interest.

\section{References}

1. Parkin DM. Global cancer statistics in the year 2000. Lancet Oncol. 2001;2:533-536.

2. National Cancer Registry Programme Consolidated report of the population based cancer registries 1990-1996. New Delhi: Indian Council of Medical Research; 2001. 13 p. 
3. Ferlay J SH, Bray F, Forman D, et al. GLOBOCAN 2008: Cancer Incidence and Mortality Worldwide. IARC Cancer Base No. 2010;1(2):1-15.

4. Agarwal G, Ramakant P. Breast Cancer Care in India: The Curren Scenario and the Challenges for the Future. Breast Care (Basel). 2008;3(1):21-27.

5. Bagchi S. Breast cancer rises in India. CMAJ. 2008;179(1):27.

6. Murthy NS, Agarwal UK, Chaudhry K, et al. A study on time trends in incidence of breast cancer - Indian scenario. Eur J Cancer Care (Engl). 2007;16(2):185-186.

7. Moore MA, Ariyaratne Y, Badar F, et al. Cancer epidemiology in South Asia-past, present and future. Asian Pac J Cancer Prev. 2010;11 Suppl 2:49-66.

8. Dhillon PK, Yeole BB, Dikshit R, et al. Trends in breast, ovarian and cervical cancer incidence in Mumbai, India over a 30-year period, 19762005: an age-period-cohort analysis. Br J Cancer. 2011;105(5):723730 .

9. Antoniou $\mathrm{AC}$, Pharoah $\mathrm{PD}$, Narod $\mathrm{S}$, et al. Breast and ovarian cancer risk to carriers of the BRCA1 5382 insC and 185 delAG and BRCA2 6174 delT mutations: a combined analysis of 22 population based studies. $J$ Med Genet. 2005;42(7):602-603.

10. Dumitrescu RG, Cotarla I. Understanding breast cancer risk-where do we stand in 2005? J Cell Mol Med. 2005;9(1):208-221.

11. Lillberg K, Verkasalo PK, Kaprio J, et al. Stressful life events and risk of breast cancer in 10,808 women. A cohort study Am J Epidemiol. 2003;157(5):415-423.

12. American Institute for Cancer Research. Physical activity and cancer risk. 2005. 64 p.

13. McTiernan. Behavioral risk factors in breast cancer: can risk be modified? The Oncologist. 2003;8(2):426-434.

14. Kelsey JL, Fischer DB, Holford TR, et al. Exogenous estrogens and other factors in the epidemiology of breast cancer. $J$ Natl Cancer Inst. 1981;67(2):327-333.

15. Van den Brandt PA, Spiegelman D, Yaun SS, et al. Pooled analysis of prospective cohort studies on height, weight, and breast cancer risk. Am J Epidemiol. 2000;152(6):514-527.

16. Lahmann PH, Hoffmann $\mathrm{K}$, Allen $\mathrm{N}$, et al. Body size and breast cancer risk: findings from the European Prospective Investigation into Cancer And Nutrition (EPIC). Int J Cancer. 2004;111(5):762-771.

17. Eliassen AH, Colditz GA, Rosner B, et al. Adult weight change and risk of postmenopausal breast cancer. JAMA. 2006;296(2):193-201.

18. Maruti SS, Willett WC, Feskanich D, et al. A prospective study of age-specific physical activity and premenopausal breast cancer. $J$ Natl Cancer Inst. 2008;100(10):728-737.

19. Bernstein L, Patel AV, Ursin G, et al. Lifetime recreational exercise activity and breast cancer risk among black women and white women. $J$ Natl Cancer Inst. 2005;97(22):1671-1679.

20. Margolis KL, Mucci L, Braaten T, et al. Physical activity in different periods of life and the risk of breast cancer: the Norwegian-Swedish Women's Lifestyle and Health cohort study. Cancer Epidemiol Biomarkers Prev. 2005;14(1):27-32.

21. McTiernan A, Kooperberg C, White E, et al. Recreational physical activity and the risk of breast cancer in postmenopausal women: the Women's Health Initiative Cohort Study. JAMA. 2003;290(10):13311336
22. Chaturvedi P. Does smoking increase the risk of breast cancer? Lancet Oncol. 2003;4(3):657-658.

23. Johnson $\mathrm{KC}$, Miller AB, Collishaw NE, et al. Active smoking and secondhand smoke increase breast cancer risk: the report of the Canadian Expert Panel on Tobacco Smoke and Breast Cancer Risk (2009). Tob Control. 2011;20(1):e2.

24. Hamajima N, Hirose $\mathrm{K}$, Tajima $\mathrm{K}$, et al. Alcohol, tobacco and breast cancer-collaborative reanalysis of individual data from 53 epidemiological studies, including 58,515 women with breast cancer and 95,067 women without the disease. Br J Cancer. 2002; 87(11):1234 1245 .

25. Thiébaut AC, Kipnis V, Chang SC, et al. Dietary fat and postmenopausal invasive breast cancer in the National Institutes of Health-AARP Diet and Health Study cohort. J Natl Cancer Inst. 2007;99(6):451-462.

26. Cho E, Chen WY, Hunter DJ, et al. Red meat intake and risk of breast cancer among premenopausal women. Arch Intern Med. 2006;166(20):2253-2259.

27. Taylor EF, Burley VJ, Greenwood DC, Cade JE. Meat consumption and risk of breast cancer in the UK Women's Cohort Study. Br J Cancer 2007;96(7):1139-1146.

28. Shin MH, Holmes MD, Hankinson SE, et al. Intake of dairy products, calcium, and vitamin d and risk of breast cancer. J Natl Cancer Inst. 2002 94(17):1301-1311.

29. Lin J, Manson JE, Lee IM, et al. Intakes of calcium and vitamin D and breast cancer risk in women. Arch Intern Med. 2007;167(10):10501059

30. Missmer SA, Smith-Warner SA, Spiegelman D, et al. Meat and dairy food consumption and breast cancer: a pooled analysis of cohort studies. Int J Epidemiol.2002;3(1):78-85.

31. Chlebowski RT, Johnson KC, Kooperberg C, et al. Calcium plus vitamin D supplementation and the risk of breast cancer. $J$ Natl Cancer Inst. 2008;100(22):1581-1591.

32. Wu AH, Yu MC, Tseng CC, et al. Epidemiology of soy exposures and breast cancer risk. Br J Cancer. 2008;98(1):9-14.

33. Kushi LH, Fee RM, Sellers TA, Zheng W, Folsom AR. Intake of vitamins $\mathrm{A}, \mathrm{C}$, and $\mathrm{E}$ and postmenopausal breast cancer. The Iowa Women's Health Study. Am J Epidemiol. 1996;144(2):165-174.

34. Ganmaa D, Willett WC, Li TY, et al. Coffee, tea, caffeine and risk of breast cancer: a 22-year follow-up. Int J Cancer. 2008;122(9):20712076.

35. Colditz GA, Rosner B. Cumulative risk of breast cancer to age 70 years according to risk factor status: data from the Nurses' Health Study. Am J Epidemiol. 2000;152(10):950-964.

36. Hsieh CC, Trichopoulos D, Katsouyanni K, et al. Age at menarche, age at menopause, height and obesity as risk factors for breast cancer: associations and interactions in an international case-control study. Int $J$ Cancer: 1990;46(5):796-800.

37. Breast cancer and hormone replacement therapy: collaborative reanalysis of data from 51 epidemiological studies of 52,705 women with breast cancer and 108,411 women without breast cancer. Collaborative Group on Hormonal Factors in Breast Cancer. Lancet. 1997;350(9084):10471059

38. Brinton LA, Schairer C, Hoover RN, et al. Menstrual factors and risk of breast cancer. Cancer Invest. 1988; 6(3):245-254.

39. Gammon MD, Thompson WD. Infertility and breast cancer: a populationbased case-control study. Am J Epidemiol. 1990;132(4):708-716. 
40. Rossing MA, Daling JR, Weiss NS, et al. Risk of breast cancer in a cohort of infertile women. Gynecol Oncol. 1996;60(1):3-7.

41. Rosner B, Colditz GA, Willett WC. Reproductive risk factors in a prospective study of breast cancer: the Nurses' Health Study. Am J Epidemiol. 1994;139(8):819-35.

42. Bruzzi P, Negri E, La Vecchia C, et al. Short term increase in risk of breast cancer after full term pregnancy. BMJ. 1988; 297:1096-1098.

43. Beral V, Bull D, Doll R, et al. Breast cancer and abortion: collaborative reanalysis of data from 53 epidemiological studies, including 83000 women with breast cancer from 16 countries. Lancet. 2004;363(9414):1007-1016

44. Paoletti X, Clavel Chapelon F. Induced and spontaneous abortion and breast cancer risk: results from the $\mathrm{E} 3 \mathrm{~N}$ cohort study. Int $J$ Cancer. $2003 ; 106(2): 270-276$

45. Collaborative Group on Hormonal Factors in Breast Cancer. Breas cancer and breastfeeding: collaborative reanalysis of individual data from 47 epidemiological studies in 30 countries, including 50302 women with breast cancer and 96973 women without the disease. Lancet. 2002;360(9328):187-195.

46. Lippman ME, Krueger KA, Eckert S, et al. Indicators of lifetime estrogen exposure: effect on breast cancer incidence and interaction with raloxifene therapy in the multiple outcomes of raloxifene evaluation study participants. J Clin Oncol. 2001;19(12):3111-3116.

47. Eliassen AH, Missmer SA, Tworoger SS, et al. Endogenous steroid hormone concentrations and risk of breast cancer among premenopausal women. J Natl Cancer Inst. 2006;98(19):1406-1415.

48. Zmuda JM, Cauley JA, Ljung BM, et al. Bone mass and breast cancer risk in older women: differences by stage at diagnosis. J Natl Cancer Inst. 2001;93(12):930-936.
49. Irwin ML, Aiello EJ, McTiernan A, et al. Physical activity, body mass index, and mammographic density in postmenopausal breast cancer survivors. J Clin Oncol. 2007;25(9):1061-1066.

50. Breast cancer and hormone replacement therapy: collaborative reanalysis of data from 51 epidemiological studies of 52,705 women with breast cancer and 108,411 women without breast cancer. Collaborative Group on Hormonal Factors in Breast Cancer. Lancet. 1997;350(9084):10471059 .

51. Beral V, Million Women Study Collaborators. Breast cancer and hormone-replacement therapy in the Million Women Study. Lancet. 2003;362(9382):419-427.

52. Chlebowski RT, Anderson GL, Gass M, et al. Estrogen plus progestin and breast cancer incidence and mortality in postmenopausal women. JAMA. 2010;304(15):1684-1692.

53. Hansen J. Increased breast cancer risk among women who work predominantly at night. Epidemiology. 2001;12(1):74-77.

54. Schernhammer ES, Laden F, Speizer FE, et al. Rotating night shifts and risk of breast cancer in women participating in the nurses' health study. J Natl Cancer Inst. 2001 93(20):1563-1568.

55. Megdal SP, Kroenke $\mathrm{CH}$, Laden F, et al. Night work and breas cancer risk: a systematic review and meta-analysis. Eur J Cancer. 2005;41(13):2023-2032.

56. Straif K, Baan R, Grosse Y, et al. Carcinogenicity of shift-work, painting, and fire-fighting. Lancet Oncol. 2007;8(12):1065-1066. 